\title{
Malnutrition in hospitals: the cost of implementing MUST screening
}

\author{
J. C. Abayomi ${ }^{1,2}$, S. Judd ${ }^{3}$, L. Hill ${ }^{1}$ and A. F. Hackett ${ }^{2}$ \\ ${ }^{1}$ Liverpool Women's Hospital, Crown Street, Liverpool L8 7SS, UK, ${ }^{2}$ Liverpool John Moores University, Faculty \\ of Education, Community and Leisure, Barkhill Road, Liverpool L17 6BD, UK and ${ }^{3}$ Liverpool Primary Care Trust, \\ Liverpool, $U K$
}

Despite a multitude of guidelines and policies published in recent years, malnutrition remains a major problem in National Health Service hospitals. In the general population it is estimated that one in seven older individuals are at risk of malnutrition and between $10 \%$ and $60 \%$ of patients are malnourished on admission to hospital ${ }^{(1)}$. The British Association for Parenteral and Enteral Nutrition (BAPEN) and National Institute for Health and Clinical Excellence (NICE) recommend screening all hospital patients using a Malnutrition Universal Screening Tool (MUST) to identify those at risk of malnutrition ${ }^{(2,3)}$, since nutritional interventions produce important clinical benefits, once patients are identified by screening ${ }^{(1)}$. The aim of the present study was to identify the number of patients likely to be identified as 'at risk' of undernutrition in a stand-alone women's hospital and to calculate the costs associated with dietetic care for such patients. All patients admitted to the gynaecology ward in one particular week were assessed using MUST and women were classified as 'possibly at risk' or 'at risk', depending on the risk score. Pregnant women were identified as 'at risk' from their BMI at booking-in (appointment scheduled at 10-14 weeks of gestation). Those women with BMI $<20 \mathrm{~kg} / \mathrm{m}^{2}$ and $<18.5 \mathrm{~kg} / \mathrm{m}^{2}$ were classified as 'possibly at risk' or 'at risk' respectively ${ }^{(2)}$. Results are shown in the Table.

Table. Prevalence of nutritionally 'at risk' patients by directorate per week

\begin{tabular}{|c|c|c|c|c|c|}
\hline \multirow[b]{2}{*}{ Directorate } & \multicolumn{2}{|c|}{ 'Possibly at risk' } & \multicolumn{2}{|c|}{ 'At risk' } & \multirow[b]{2}{*}{ Total referrals per week } \\
\hline & $n$ & $\%$ & $n$ & $\%$ & \\
\hline Gynaecology (not oncology) & 4 & 16.6 & 7 & 27.7 & Eleven from twenty-five beds \\
\hline Maternity & 6 & 3.8 & 16 & 10.7 & Twenty-two from 152 beds \\
\hline
\end{tabular}

The prevalence of undernutrition was greater among patients in gynaecology, but larger numbers of patients in maternity would generate more referrals. If all patients required an average of $2 \mathrm{~h}$ dietetic intervention (for assessment, monitoring, treatment and advice), a total of sixty-six extra hours per week would be needed. BDA guidelines state that direct patient contact should be $55-60 \%$ of the workload ${ }^{(4)}$, hence a total of $92 \mathrm{~h} /$ week or 2.5 whole time equivalent (WTE) dietitians. The women's hospital currently only screens patients in oncology and funds an oncology dietetic service with 0.5 WTE. If all hospital patients were screened for malnutrition using MUST a $500 \%$ increase in dietetic staff and related resources would be required to implement this screening at a cost of about $£ 102100$ per year. This estimate does not include initial start-up costs required to implement the screening, such as staff training or audit time to evaluate the impact. Despite the recommendations of NICE and BAPEN, it would be unethical to introduce screening at the hospital until adequate funding is secured to allow sufficient resources to deal with the problem.

1. Elia M, Baxter JP, Jackson A et al. (2000) Guidelines for Detection and Management of Malnutrition, pp. 8-9. Redditch, Worcs.: BAPEN.

2. Elia M, Zellipour L \& Stratton RJ (2005) Clin Nutr 24, 867-884.

3. National Institute for Health and Clinical Excellence (2006) Nutrition Support in Adults. NICE: London.

4. British Dietetic Association (2006) www.bda.uk.com 